\title{
Phytochemical analysis of Ardisia silvestris leaf extracts and their antioxidant and antibacterial activities
}

\author{
Biet V. Huynh ${ }^{1 *}$, Phuong N. T. Nguyen ${ }^{2}$, Nga T. T. Nguyen ${ }^{3,4}$, \\ Toan Q. Truong ${ }^{1}$, \& Hong C. V. Phung ${ }^{1}$ \\ ${ }^{1}$ Research Institute for Biotechnology and Environment, Nong Lam University, Ho Chi Minh City, Vietnam \\ ${ }^{2}$ Faculty of Applied Science, Ton Duc Thang University, Ho Chi Minh City, Vietnam \\ ${ }^{3}$ Department of Biotechnology, Nong Lam University, Ho Chi Minh City, Vietnam \\ ${ }^{4}$ Faculty of Agriculture, Vietnam National University of Forestry (Dong Nai Campus), Dong Nai, Vietnam
}

\begin{abstract}
ARTICLE INFO
Research Paper

Received: December 16, 2019

Revised: February 10, 2020

Accepted: May 13, 2020

Keywords

Antibacterial activities

Antioxidant

Ardisia silvestris

Phytochemical analysis

\section{${ }^{*}$ Corresponding author}

Huynh Van Biet

Email: hvbiet@hcmuaf.edu.vn

\section{ABSTRACT}

The phytochemical analysis and antibacterial and antioxidant activity of Ardisia silvestris extracts were carried out. The bioactive compounds of Ardisia silvestris leaves were extracted with petroleum ether, ethyl acetate, ethanol and water by immersion and microwave method. The DPPH method was used to determine the antioxidant activity of $\mathrm{Ar}$ disia silvestris extracts. The antibacterial properties of Ardisia silvestris tested against of Staphylococcu saureus, Samonella sp., and Escherichia coli were determined by using agar diffusion method. The agar diffusion method was used to determine the antibacterial effects of both plant extracts on the test organisms. The results showed that Ardisia silvestris leaves contained compounds such as essential oils, fats, alkaloids, flavonoids, coumarins, tannins, anthocyanoids, carotenoids, organic acids, reducing agents, proanthocyanidins, saponins and anthraquinones. Ardisia silvestris leaves had a total polyphenol content of $0.26 \%$ dry matter, tannin of $8.8 \%$, and a total flavonoid of $1.44 \mathrm{mg} / \mathrm{g}$. The ethyl acetate extract and water extract of the leaves had the antioxidant activity and were 4.2 and 4.4 times lower than ascorbic acid, respectively. The ethyl acetate extract of Ardisia silvestris had the highest oxidative activity. The zone of inhibition of the plant extract diameters at the concentration of $100 \mathrm{pl} / \mathrm{ml}$ ranged between $9.67 \mathrm{~mm}$ and $20.67 \mathrm{~mm}$ for ethyl acetate and ethanol extracts, respectively on E.coli. Similarly, the zones of inhibitionof ethyl acetate and ethanol extracts diameters were 14.67 and $15.33 \mathrm{~mm}$, respectively on Samonella sp., however, it was not shown for Staphylococus aureus.
\end{abstract}

Cited as: Huynh, B. V., Nguyen, P. N. T., Nguyen, N. T. T., Truong, T. Q., \& Phung, H. C. V. (2020). Phytochemical analysis of Ardisia silvestris leaf extracts and their antioxidant and antibacterial activities. The Journal of Agriculture and Development 19(4), 28-35. 


\title{
Phân tích thành phần hóa thực vật và xác định khả năng chống oxy hóa và kháng khuẩn của dịch chiết từ lá của cây khôi nhung (Ardisia silvestris Pitard)
}

\author{
Huỳnh Văn Biết ${ }^{1 *}$, Nguyễn Thị Ngọc Phương ${ }^{2}$, Nguyễn Thị Thanh Nga $^{3,4}$, \\ Trương Quang Toản ${ }^{1} \&$ Phùng Võ Cẩm Hồng ${ }^{1}$ \\ ${ }^{1}$ Viện Nghiên Cứu Công Nghệ Sinh Học Và Môi Trường, Trường Đại Học Nông Lâm TP. HCM, TP. Hồ \\ Chí Minh \\ ${ }^{2}$ Khoa Khoa Học Ứng Dụng, Trường Đại Học Tôn Đức Thắng, TP. Hồ Chí Minh \\ ${ }^{3}$ Bộ Môn Công Nghệ Sinh Học, Trường Đại Học Nông Lâm TP.HCM, TP. Hồ Chí Minh \\ ${ }^{4}$ Khoa Nông Học, Trường Đại Học Lâm Nghiệp - Phân Hiệu Đồng Nai, Đồng Nai
}

\section{THÔNG TIN BÀI BÁO}

\section{Bài báo khoa học}

Ngày nhận: 16/12/2019

Ngày chỉnh sửa: 10/02/2020

Ngày chấp nhận: 13/05/2020

\section{Từ khóa}

Cây khôi nhung Ardisia silvestris

Chống oxy hoá

Kháng khuẩn

Phân tích hoá thực vật

\section{*Tác giả liên hệ}

Huỳnh Văn Biết

Email: hvbiet@hcmuaf.edu.vn

\section{TÓM TẮT}

Khảo sát sơ bộ thành phần hóa thực vật, định lượng một số hợp chất và xác định khả năng kháng khuẩn, khả năng kháng oxy hóa từ lá cây khôi nhung (Ardisia silvestris) đã được thực hiện. Các hợp chất của lá cây khôi nhung được ly trích với dung môi petroleum ether, ethylacetate, ethanol và nước bằng phương pháp ngâm dầm và đánh vi sóng. Khả năng chống oxy hoá của các dịch chiết lá cây khôi nhung được xác định bằng phương pháp DPPH. Khả năng kháng khuẩn Staphylococcu saureus, Samonella sp. và Escherichia coli của các cao chiết lá cây khôi nhung được xác định bằng phương pháp khuếch tán đĩa thạch. Các dung môi petroleum ether, ethyl acetate, ethanol và nước được dùng cho li trích. Kết quả cho thấy lá cây khôi nhung có chứa các hợp chất như tinh dầu, chất béo, alkaloid, flavonoid, coumarin, tanin, anthocyanoid, carotenoid, các acid hữu cơ, chất khử, proanthocyanidin, saponin và anthraquinon. Hàm lượng polyphenol có trong lá cây khôi nhung là $0,26 \%$ chất khô. Hàm lượng tanin của lá cây khôi là 8,80\%. Hàm lượng Flavonoid của lá cây khôi nhung là $1,442 \mathrm{mg} / \mathrm{g}$. Dịch chiết ethyl acetate và dịch chiết nước của lá cây khôi nhung có khả năng kháng oxy hóa, nhưng thấp hơn so với acid ascorbic lần lượt là 4,2 và 4,4 lần. Dịch chiết ethyl acetate của lá khôi nhung có hoạt tính oxy hóa cao nhất. Các dịch chiết ethyl acetate và dịch chiết ethanol thể hiện rõ tính kháng vi khuẩn thông qua đường kính vòng vô khuẩn, đối với vi khuẩn E.coli lần lượt từ $9,67 \mathrm{~mm}$ đến $20,67 \mathrm{~mm}$ và Salmonella $\mathrm{sp}$. là $14,67 \mathrm{~mm}$ và $15,33 \mathrm{~mm}$, tuy nhiên không thể hiện đối với vi khuẩn Staphylococus aureus.

\section{1. Đặt Vấn Đề}

Do có điều kiện tự nhiên đa dạng nên Việt Nam có một hệ sinh thái phong phú và tiềm năng to lớn về tài nguyên cây dược liệu. Chính vì vậy, ở nước ta, từ lâu đời, trong dân gian với trí thức sử dụng các loài dược liệu, nhiều bài thuốc quí có giá trị chữa bệnh hữu hiệu đã được lưu truyền (Do, 2004). Tuy nhiên, để đáp ứng xu hướng hiện nay về sự "Trở về với thiên nhiên" với việc sử dụng thảo dược làm thuốc ngày càng nâng cao ở trong nước và trên thế giới thì cần có các nghiên chuyên sâu và khoa học.

Cây khôi nhung (Ardisia silvestris Pitard) là loài thuộc chi Ardisia, họ Myrsinnaceae, có nhiều hoạt tính sinh học đáng quý như hoạt tính kháng khuẩn, kháng nấm, kháng virus, kháng viêm giảm đau, chống oxi hóa, chống đái tháo đường, chống loãng xương, bảo vệ thần kinh, bảo vệ gan và nhất là hoạt tính chống ung thư rất tốt (Do, 2004). Kobayashi \& de Mejía (2005) dã nhận định: Chi Ardisia - một nguồn mới cung cấp các hợp chất tăng cường sức khỏe và dược phẩm có nguồn gốc thiên nhiên quý giá. Một số nghiên cứu cho thấy 
rằng trong cây khôi nhung Ardisia silvestris có sự hiện diện của tannin, glucoside, saponin, alkaloid, chất béo, carotene, flavonoid (Nguyen, 1999; Tran, 2002). Tuy nhiên, ở Việt Nam dù đã được sử dụng làm thuốc chữa bệnh trong dân gian nhưng chưa có nhiều các nghiên cứu về thành phần hóa học cũng như hoạt tính sinh học của các loài thực vật trong chi Ardisia nói chung và cây khôi nhung Ardisia silvestris riêng. Chính vì vậy, nghiên cứu sơ bộ thành phần hóa thực vật, định lượng một số hợp chất và xác định khả năng kháng khuẩn, khả năng kháng oxy hóa từ lá cây khôi nhung được thực hiện nhằm củng cố, và cung cấp thêm các thông tin khoa học có giá trị và tin cậy về hoạt tính sinh học của cây khôi nhung, từ đó giúp cho việc khai thác sử dụng cây khôi nhung làm nguồn dược liệu trong thực tế có hiệu quả hơn.

\section{Vật liệu và Phương Pháp Nghiên Cứu}

\subsection{Vật liệu}

Cây khôi nhung (Ardisia silvestris Pitard) được thu thập tại Khu bảo tồn Thiên nhiên và Văn hóa Đồng Nai, Vườn quốc gia Cát Tiên và tiếp tục nuôi trồng tại nhà lưới Viện nghiên cứu Công nghệ Sinh học và Môi trường (RIBE), Trường Đại học Nông Lâm Thành phố Hồ Chí Minh. Mẫu lá được rửa sạch, sấy khô ở nhiệt độ $50^{\circ} \mathrm{C}$, sau đó được đem xay và đạt kích thước qua rây $2 \mathrm{~mm}$ được sử dụng làm nguyên liệu thí nghiệm. Vi khuẩn thử nghiệm: Các chủng vi khuẩn Samonella sp. và Escherichia coli ATCC 2592 gây bệnh tiêu chảy, Staphylococus aureus ATCC 43300 gây nhiễm trùng da, được cung cấp bởi Phòng vi sinh của Viện Nghiên cứu Công nghệ Sinh học và Môi trường - Trường Đại học Nông Lâm Thành phố Hồ Chí Minh.

\subsection{Phương pháp nghiên cứu}

Xác định độ ẩm của dược liệu: theo phương pháp cân, sấy ở nhiệt độ $105^{\circ} \mathrm{C}$, đánh giá theo tiêu chuẩn Dược điển Việt Nam IV (MOH, 2010), độ ẩm của dược liệu không được quá 13\%.

Xác định độ tro toàn phần: phương pháp cân và nung dược liệu ở $550^{\circ} \mathrm{C}$, chỉ tiêu được đánh giá theo Dược điển Việt Nam IV $(\mathrm{MOH}, 2010)$, độ tro toàn phần không quá $12 \%$.

Tách chiết cao dược liệu: Tách chiết cao tổng bằng phương pháp ngâm dầm kết hợp đánh sóng siêu âm. Ngâm bột nguyên liệu (100 g) trong bình chứa bằng thủy tinh với $500 \mathrm{~mL}$ dung môi, đánh sóng siêu âm 30 phút ở $30^{\circ} \mathrm{C}$ và dể yên nhiệt độ phòng qua đêm.

Các chỉ tiêu phân tích hóa thực vật: Chuẩn bị dịch chiết với bốn dung môi petroleum ether, ethyl acetate, ethanol và nước lần lượt nhau: Chiết $10 \mathrm{~g}$ bột nguyên liệu (hoặc bã xác nguyên liệu đã được trích ly với dung môi trước) trong bình thủy tinh bằng dung môi (petroleum ether, ethyl acetate, ethanol hoặc nước) trong bồn siêu âm 30 phút (riêng đối với dung môi là nước thì được đun cất thuỷ nóng trên lò). Chiết cho đến khi dịch dung môi bốc hơi không còn vết mờ trên giấy thấm. Gộp dịch chiết lại đem cô quay còn khoảng $50 \mathrm{~mL}$ dịch chiết (Nguyen, 2007). Các cao chiết này được sử dụng cho các thí nghiệm tiếp theo.

Định tính các nhóm chất: tinh dầu, chất béo, alkaloid, flavonoid, coumarin, tanin, anthocyanoid, carotenoid, các acid hữu cơ, chất khử, proanthocyanidin, saponin và anthraquinon (Nguyen, 2007).

Xác định hàm lượng polyphenol: Dùng thuốc thử Folin - Ciocalteu (FC) để xác định các polyphenol trong dịch chiết nước của lá cây khôi, acid gallicđược làm chất hiệu chuẩn, kết quả trung bình của 3 lần lặp lại (Fu \& ctv., 2011).

Xác định hàm lượng tannin: Tanin bị $\mathrm{KMnO}_{4}$ oxy hóa ở môi trường acid. Điểm kết thúc định lượng được xác định bằng chỉ thị màu sulfo indigo. Từ lượng KMnO4 tiêu thụ, tính ra lượng chất bị oxy hóa trong dược liệu dựa trên chất tanin chuẩn, quá trình chuẩn độ kết thúc khi dung dịch thử chuyển sang màu vàng, kết quả trung bình của 3 lần lặp lại (Le \& ctv., 2005).

Xác định hàm lượng flavonoid: với đường chuẩn Rutin, kết quả trung bình của 3 lần lặp lại (Chang \& ctv., 2002).

Đánh giá hoạt tính kháng oxy hóa - phương pháp thử nghiệm DPPH: với Acid ascorbic (Merck, Germany) được sử dụng làm chất chuẩn đối chiếu.

Đánh giá khả năng kháng khuẩn: Xác định khả năng kháng khuẩn của các dịch chiết lá khôi nhung đối với vi khuẩn Escherichia coli, Salmonella sp. và Staphylococus aureus với mật số là $106 \mathrm{cfu} / \mathrm{mL}$ và đánh giá khả năng kháng khuẩn theo phương pháp cấy trang trên bề mặt thạch có đục lỗ (đường kính $5 \mathrm{~mm}$, chứa $100 \mu \mathrm{L}$ dịch chiết mẫu) của từng nghiệm thức. Đo đường kính vòng vô khuẩn đánh giá mức độ kháng khuẩn của dịch chiết lá cây khôi nhung. 
Bảng 1. Kết quả độ ẩm và tro toàn phần của mẫu nguyên liệu lá khôi

\begin{tabular}{lccc}
\hline Chỉ tiêu & Tỷ lệ $(\%)$ & Tiêu chuẩn dược liệu (\%) & Đánh giá \\
\hline Độ ầm mẫu nguyên liệu & $5,54 \pm 0,22$ & $<13$ & Đạt \\
Độ trò toàn phần & $10,73 \pm 0,75$ & $<12$ & Đạt \\
\hline
\end{tabular}

Xử lý số liệu: các số liệu được phân tích ANOVA và trắc nghiệm phân hạng Tukey.

\section{Kết Quả và Thảo Luận}

\section{1. Đánh giá độ ẩm và tro toàn phần của mẫu nguyên liệu}

Độ ẩm và tro toàn phần của mẫu cao chiết cây khôi nhung được trình bày trong Bảng 1 . Kết quả cho thấy độ ẩm mẫu cao chiết lá khôi nhung khôi đạt trung bình là $5,54 \pm 0,22 \%$ và độ tro toàn phần là $10,73 \pm 0,75 \%$. Kết quả này phù hợp với tiêu chuẩn cao chiết theo quy chuẩn của Dược điển Việt Nam IV (MOH, 2010).

\section{2. Định tính sơ bộ thành phần hóa học của nguyên liệu}

Lá cây khôi nhung sau khi xay nhuyễn được chiết với các hệ dung môi khác nhau theo độ phân cực tăng dần kết hợp đánh sóng siêu âm. Các loại dịch chiết petroleum ether, dịch chiết ethyl acetate, dịch chiết ethanol, dịch chiết nước được dùng để thử nghiệm định tính các hợp chất. Kết quả được trình bày trong Bảng 2 .

Kết quả khảo sát sơ bộ hóa thực vật của lá cây khôi nhung cho thấy sự xuất hiện của các hợp chất như tinh dầu, chất béo, alkaloid, flavonoid, coumarin, tanin, anthocyanoid, carotenoid, các acid hữu cơ, chất khử, proanthocyanidin, saponin và anthraquinon. Ngoài một số hợp chất tương tự đã được công bố trước đây như tanin, saponin, alkaloid, đường khử, chất béo, carotene, flavonoid (Nguyen, 1999), kết quả nghiên cứu này đã cho thấy rằng trong cây khôi nhung còn có các hợp chất khác như anthocyanoid, proanthocyanidin, anthraquinon. Trong dịch chiết với nước, phần lớn có sự hiện diện của các hợp chất khảo sát ngoại trừ chất béo và coumarin. Khảo sát thành phần hóa học của các hợp chất trong thực vật có ý nghĩa quan trọng trong xác định các nhóm chất và tác dụng của các chất này, giúp cho quá trình xác định cấu trúc, chức năng và việc tách chiết từng chất dễ dàng và ít tốn kém thời gian, chi phí và đồng thời qua việc xác định sự hiện diện của các hợp chất trong lá cây khôi nhung cũng góp phần nâng cao giá trị sử dụng nhờ những hợp chất có trong lá cây khôi nhung nói riêng, cây dược liệu nói chung.

\section{3. Định lượng hàm lượng polyphenol, tanin, flavonoid trong dịch chiết lá cây khôi nhung}

Hàm lượng polyphenol trong lá cây khôi được xác định dựa trên đường chuẩn acid gallic (Hình 1)) với dãy nồng độ $10 ; 20 ; 30 ; 40 ; 50 \mu \mathrm{g} / \mathrm{mL}$ với phương trình hồi quy tuyến tính $\mathrm{y}=0,0216 \mathrm{x}$ $+0,0527$; với $\mathrm{R}^{2}=0,9866$. Kết quả hàm lượng polyphenol trong lá cây khôi được trình bày ở Bảng 3. Hàm lượng flavanoid tổng số của mẫu được xác định dựa vào đường chuẩn rutin (Hình 2) với các thể tích 0,$4 ; 0,8 ; 1,2 ; 1,6 ; 2,0 ; 2,4 \mathrm{~mL}$, xác định được phương trình hồi quy tuyến tính y $=0,0143 \mathrm{x}+0,0177 ;$ với $\mathrm{R}^{2}=0,9904$. Kết quả về hàm lượng flavanoid tổng số của mẫu được thể hiện ở Bảng 3. Hàm lượng tannin được xác định bằng phương pháp oxy hóa. Một $\mathrm{mL}$ dung dịch $\mathrm{KMnO}_{4}$ 0,1 $\mathrm{N}$ tương ứng với $0,004157 \mathrm{~g}$ tanin tinh khiết. Kết quả về hàm lượng tanin có trong mẫu lá cây khôi được trình bày ở Bảng 3 .

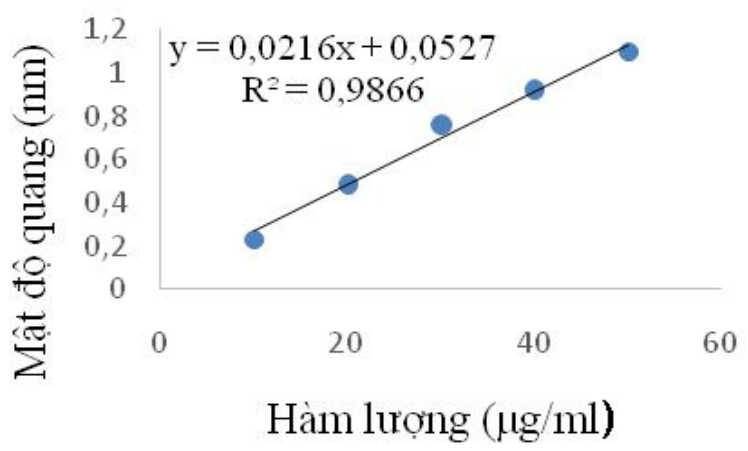

Hình 1. Đường chuẩn acid gallic.

Lá cây khôi nhung có hàm lượng polyphenol tổng số là $0,26 \%$ chất khô, tanin là $8,8 \%$, và flavonoid tổng số là $1,44 \mathrm{mg} / \mathrm{g}$ chất khô (Bảng $3)$.

Một số nghiên cứu cho thấy polyphenol là một trong những hợp chất thứ cấp chính của nhiều loài thực vật, tham gia vào một số chức năng 


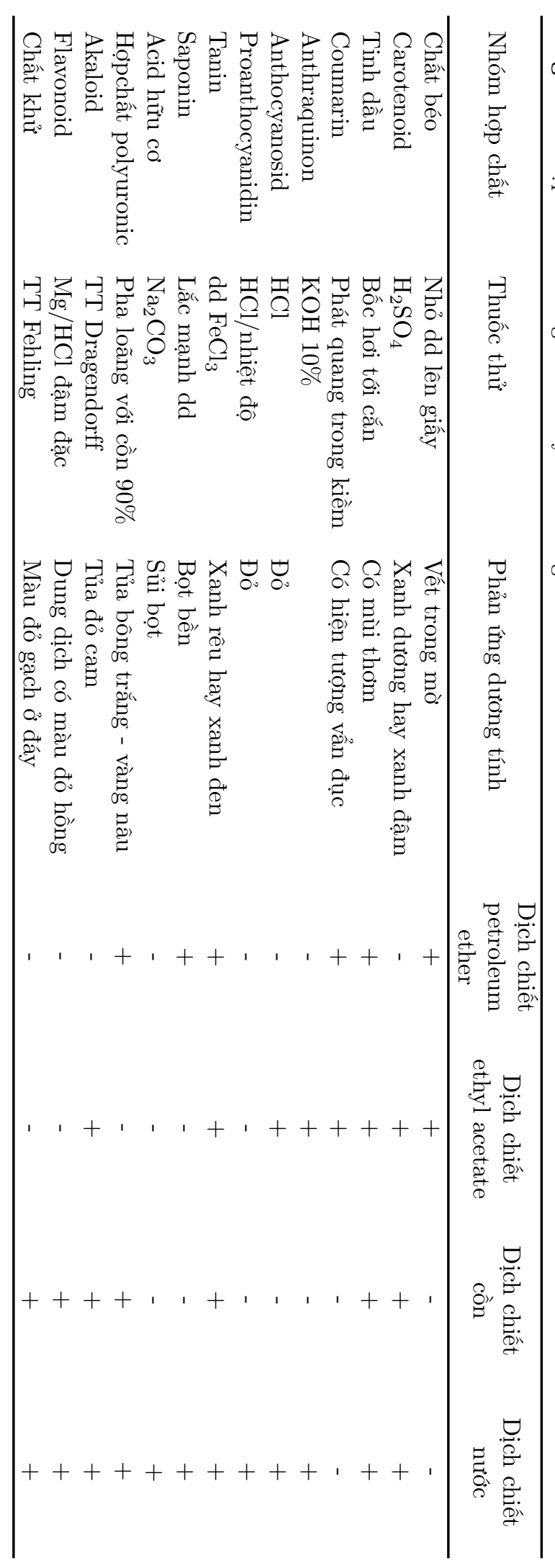

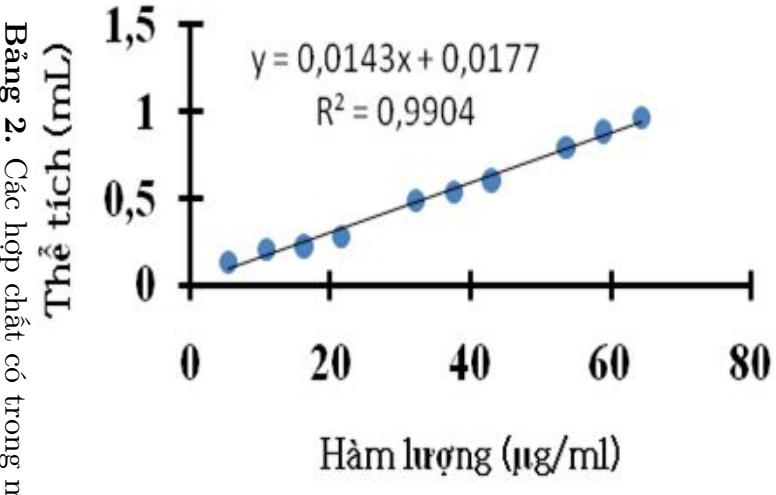

Hình 2. Đường chuẩn rutin.

क्ष.

ชิ่

¿ sinh lý như kháng oxi hóa (Bhattacharyya \& ctv., O. 2014) và có tác dụng mạnh mẽ trong hoạt tính Eháng oxi hóa (Kikuzaki \& ctv., 2002), kháng İ viêm, kháng khuẩn, kháng dị ứng, kháng lão hóa và một số bệnh liên quan tới ung thư (Dai \& Mumper, 2010). Phần lớn các hợp chất polyphenol bị ảnh hưởng bởi một số yếu tố tác động như UV, nhiệt độ, thành phần dưỡng chất và yếu tố di truyền (Ling \& Subramaniam, 2007). Hàm lượng polyphenol phụ thuộc rất nhiều vào chất lượng hay độ non già của nguyên liệu. Nguyên liệu càng non, hàm lượng polyphenol càng lớn và ngược lại. Hàm lượng polyphenol trong lá cây khôi nhung trong nghiên này thấp hơn so với thí nghiệm được thực hiện trên nguyên liệu lá chè từ non đến già là $14,63 \%$ đến $26,60 \%$ chất khô (mẫu được sấy ở $70^{\circ} \mathrm{C}$ ) (Giang \& ctv., 2011).

Tương tự, tanin có tính kháng khuẩn được dùng trong điều trị các bệnh viêm ruột, tiêu chảy. Tanin thường có nhiều trong búp sim, búp ổi, vỏ ổi và vỏ măng cụt, vì vậy đây là những nguồn dược liệu tiêu biểu đã được dân gian sử dụng trong việc điều trị các bệnh này. Phối hợp với tính làm săn se, tanin còn được dùng để làm thuốc súc miệng khi niêm mạc miệng, họng bị viêm loét hoặc chữa vết loét do người bệnh nằm lâu. Theo dược liệu Việt Nam hàm lượng tanin có trong lá ổi từ $7-10 \%$. Như vậy, hàm lượng tanin của lá khôi nhung đạt 8,8\% (Bảng 3) tương đương với lượng tanin trong lá ổi.

Một trong những hợp chất khá phổ biến và có nhiều chức năng trong nhiều loài thực vật đó là flavonoid. Trong thực vật bậc cao, flavonoids tham gia vào lọc tia cực tím (UV), cộng sinh cố định đạm và sắc tố của hoa (Grotewold, 2007). Flavonoids có thể hoạt động như một chất chuyển hoá hóa học hoặc điều chỉnh sinh lý, và cũng có 
Bảng 3. Kết quả định lượng hợp chất polyphenol, flavonoid và tanin có trong lá cây khôi

\begin{tabular}{lccc}
\hline Loại & Polyphenol (\% chất khô) & $\begin{array}{c}\text { Tanin }(\% \mathrm{w} / \mathrm{w} \text { chất } \\
\text { khô })\end{array}$ & $\begin{array}{c}\text { Flavonoid tổng số } \\
(\mathrm{mg} / \mathrm{g} \text { chất khô })\end{array}$ \\
\hline Mẫu lá khôi $(\mathrm{n}=3)$ & $0,26 \pm 0,05$ & $8,80 \pm 0,4$ & $1,44 \pm 0,19$ \\
\hline
\end{tabular}

thể hoạt động như các chất ức chế chu kỳ tế bào. Trong nghiên cứu này, hàm lượng flavonoid trung bình của dịch chiết từ lá cây khôi nhung đạt 1,442 \pm 0,19 (mg/g) (Bảng 3) thấp hơn so với kết quả nghiên cứu hàm lượng flavonoid từ lá cây rau sam (P. oleraceal.) (1,76 mg/g) (Zhu \& ctv., 2009).

\subsection{Khả năng kháng oxy hóa của dịch chiết lá cây khôi nhung}

Các dịch chiết được dùng thử nghiệm đều có hoạt tính sinh học khác nhau. Giá trị $\mathrm{IC}_{50}$ của vitamin $\mathrm{C}$ (acid ascorbic) là 7,207 $\mu \mathrm{g} / \mathrm{mL}$. Tiếp theo là ehyl acetate $(\mathrm{EA})$ và nước lần lượt là 30,51 $\mu \mathrm{g} / \mathrm{mL}$ và $31,868 \mu \mathrm{g} / \mathrm{mL}$. Cao nhất là ehanol (Eth) là $48,144 \mu \mathrm{g} / \mathrm{mL}$. Giá trị $\mathrm{IC}$ càng cao thể hiện khả năng kháng oxy hóa càng thấp. Theo đồ thị ở Hình 3 dựa vào giá trị $\mathrm{IC}_{50}$ thấy được dung môi ehyl acetate và nước có khả năng kháng oxy hóa thấp hơn lần lượt 4,2 lần và 4,4 lần so với acid ascorbic. Ethanol (Eth) có khả năng kháng oxy hóa thấp nhất, thấp hơn $\mathrm{IC}_{50}$ của acid ascorbic là 6,7 lần. Dịch chiết với Petroleum ether không cho kết quả kháng oxy hóa.

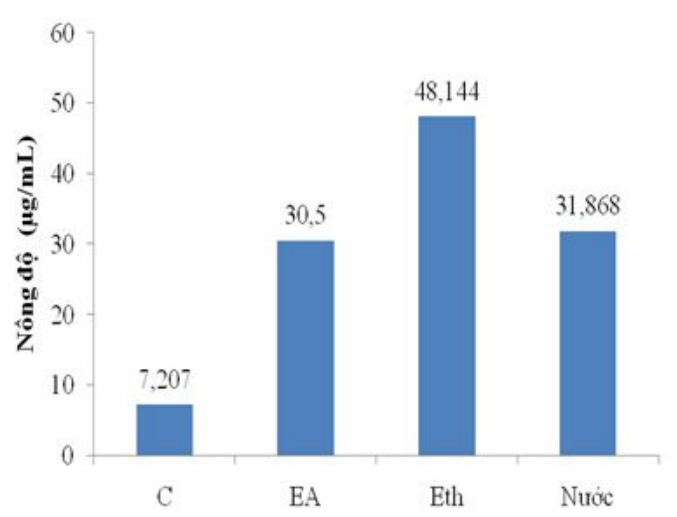

Hình 3. Đồ thị thể hiện hoạt tính kháng oxy hóa của các dịch chiết thông qua giá trị $\mathrm{IC}_{50}$. C: Acid ascorbic, EA: dịch chiết với dung môi Ethyl acetate, Eth: dịch chiết với dung môi ethanol, Nước: dịch chiết với nước.

Các dịch chiết được dùng thử nghiệm đều có hoạt tính sinh học khác nhau. Giá trị $\mathrm{IC}_{50}$ của vitamin $\mathrm{C}$ (acid ascorbic) là $7,207 \mu \mathrm{g} / \mathrm{mL}$. Tiếp theo là ehyl acetate $(\mathrm{EA})$ và nước lần lượt là 30,51 $\mu \mathrm{g} / \mathrm{mL}$ và $31,868 \mu \mathrm{g} / \mathrm{mL}$. Cao nhất là ehanol (Eth) là 48,144 $\mathrm{\mu g} / \mathrm{mL}$. Giá trị IC càng cao thể hiện khả năng kháng oxy hóa càng thấp. Theo đồ thị ở Hình 3 dựa vào giá trị $\mathrm{IC}_{50}$ thấy được dung môi ehyl acetate và nước có khả năng kháng oxy hóa thấp hơn lần lượt 4,2 lần và 4,4 lần so với acid ascorbic. Ethanol (Eth) có khả năng kháng oxy hóa thấp nhất, thấp hơn $\mathrm{IC}_{50}$ của acid ascorbic là 6,7 lần. Dịch chiết với Petroleum ether không cho kết quả kháng oxy hóa.

\section{5. Đánh giá khả năng kháng khuẩn của dịch chiết lá cây khôi nhung}

Bốn loại dịch chiết lá cây khôi với các dung môi petroleum ether, ethyl acetate, ethanol được đánh giá khả năng ức chế vi khuẩn $E$. coli, $S a$ monella sp., S. aureus. Kết quả được trình bày ở Bảng 4.

Kết quả ở Bảng 4 cho thấy, đối với vi khuẩn $E$. coli các dịch chiết đều có khả năng ức chế ngoại trừ dịch chiết petroleum ether không thể hiện sự khác biệt có ý nghĩa thống kê giữa các nghiệm thức. Trong đó, đường kính trung bình vòng vô khuẩn của dịch chiết ethyl acetate là lớn nhất, tiếp đến là của dịch chiết ethanol và sau đó là của dịch chiết nước lần lượt tương ứng là 20,67; 9,67 và $6,67 \mathrm{~mm}$.

Tương tự, đối với vi khuẩn Samonella sp., đường kính vòng vô khuẩn của các dịch chiết rất khác nhau (Bảng 4), từ nhỏ đến lớn lần lượt là 0 ; 7,$67 ; 14,67 ; 15,33 \mathrm{~mm}$ tương ứng của dịch chiết petroleum ether, nước, ethanol và ethyl acetate. Trong đó, đường kính vòng vô khuẩn của dịch chiết ethanol và ethyl acetate không có sự khác biệt có ý nghĩa thống kê. Hai dịch chiết này có tính kháng mạnh đối với vi khuẩn Samonella sp.

Trong khi đó, cả bốn dịch chiết lá cây khôi nhung trong nghiên cứu này đều không có khả năng ức chế đối với vi khuẩn Staphylococus aureus điều này có thể do nồng độ các hoạt chất có trong dịch chiết thấp. Trong nghiên cứu trước đây, kết quả cho thấy dịch chiết của cây Ardisia elliptica không có khả năng kháng khuẩn đối với $E$. coli và Staphylococus aureus (Al-Abd \& ctv., 2017). 
Bảng 4. Khả năng kháng khuẩn của các dịch chiết với các dung môi khác nhau

\begin{tabular}{lcccc}
\hline \multirow{2}{*}{ Vi khuẩn } & \multicolumn{4}{c}{ Đường kính vòng kháng khuẩn $(\mathrm{mm})$} \\
\cline { 2 - 5 } & $\begin{array}{c}\text { Dịch chiết } \\
\text { petroleum ether }\end{array}$ & $\begin{array}{c}\text { Dịch chiết ethyl } \\
\text { acetate }\end{array}$ & $\begin{array}{c}\text { Dịch chiết } \\
\text { ethanol }\end{array}$ & Dịch chiết nước \\
\hline E. coli & - & $20,67^{\mathrm{a}} \pm 0,94$ & $9,67^{\mathrm{b}} \pm 0,47$ & $6,67^{\mathrm{c}} \pm 0,47$ \\
Salmonella $\mathrm{sp.}$ & - & $15,33^{\mathrm{a}} \pm 0,47$ & $14,67^{\mathrm{a}} \pm 0,48$ & $7,67^{\mathrm{b}} \pm 0,49$ \\
S. aureus & - & - & - & - \\
\hline "-": không có giá trị. & & & & \\
a-b Trong cùng một hàng, các giá trị có các ký tự khác nhau thì có sự khác biệt có ý nghĩa thống kê với $P<0,05$.
\end{tabular}

\section{Kết Luận}

Lá cây khôi nhung Ardisia silvestris Pitard có độ ẩm và độ tro toàn phần đạt tiêu chuẩn dược liệu. Trong lá cây khôi nhung có chứa các hợp chất tinh dầu, chất béo, alkaloid, flavonoid, coumarin, tanin, anthocyanoid, carotenoid, các acid hữu cơ, chất khử, proanthocyanidin, saponin và anthraquinon. Trong lá cây khôi nhung, hàm lượng polyphenol tổng số là $0,26 \%$ chất khô, tanin là $8,8 \%$, và flavonoid tổng số là $1,44 \mathrm{mg} / \mathrm{g}$. Dịch chiết ethyl acetate và dịch chiết nước của lá cây khôi nhung có khả năng kháng oxy hóa thấp hơn so với acid arcobic lần lượt 4,2 lần và 4,4 lần. Dịch chiết ethyl acetate và dịch chiết ethanol thể hiện vòng vô khuẩn đối với vi khuẩn $E$. coli (từ 9,67 $\mathrm{mm}$ đến $20,67 \mathrm{~mm}$ ) và Salmonella $\mathrm{sp}$. (từ 14,67 mm đến 15,33 mm), tuy nhiên không thể hiện đối với vi khuẩn Staphylococus aureus. Việc cô lập các đơn chất trong lá cây khôi nhung đang được thực hiện và cần được nghiên cứu đánh giá sâu hơn hoạt tính sinh học của các đơn chất này.

\section{Lời Cảm Ơn}

Nhóm tác giả xin chân thành cảm ơn Trường Đại học Nông Lâm TP.HCM đã cấp kinh phí cho nghiên cứu này; cảm ơn Ban Lãnh đạo, Cán bộ công tác tại Khu bảo tồn Thiên nhiên và Văn hóa Đồng Nai, Vườn quốc gia Cát Tiên đã hỗ trợ trong việc thu thập mẫu cây khôi nhung.

\section{Tài Liệu Tham Khảo (References)}

Al-Abd, N. M., Nor, Z. M., Mansor, M., Zajmi, A., Hasan, M. S., Azhar, F., \& Kassim, M. (2017). Phytochemical constituents, antioxidant and antibacterial activities of methanolic extract of Ardisia elliptica. Asian Pacific Journal of Tropical Biomedicine 7(6), 569-576.

Bhattacharyya, P., Kumaria, S., Diengdoh, R., \& Tandon, P. (2014). Genetic stability and phytochemical analysis of the invitro regenerated plants of Dendrobium nobile Lindl., an endangered medicinal orchid. Meta Gene 2, 489-504.
Chang, C., Yang, M., Wen, H., \& Chem, J. (2002). Estimation of flavonoid total content in propolis by two complementary colorimetric methods. Journal of Food and Drug Analysis 10(3), 178-182.

Dai, J., \& Mumper, R. J. (2010). Plant phenolics: extraction, analysis and their antioxidant and anticancer properties. Molecules 15, 7313-7352.

Do, T. L. (2004). Vietnamese medicinal plants and herbs. Ha Noi, Vietnam: Medical Publishing House.

Fu, L., Xu, B. T., Xu, X. R., Gan, R. Y., Zhang, Y., Xia, E. Q., \& Li, H. B. (2011). Antioxidant capacities and total phenolic contents of 62 fruits. Food Chemistry 129(2), 345-350.

Giang, K. T., Nguyen, M. T., Pham, H. V., Pham, D. T. H., \& Duez, P. (2011). Effect of quality of material on polyphenol content and antibacterial activity of $\mathrm{pH}$ tea varieties. Journal of Science and Development 9(2), 258-264.

Grotewold, E. (2007). The science of flavonoids. New York, USA: Springer Publishing House.

Kikuzaki, H., Hisamoto, M., Hirose, K., Akiyama, K., \& Taniguchi, H. (2002). Antioxidant properties of ferulic acid and its related compounds. Journal of Agricultural and Food Chemistry 50, 2161-2168.

Kobayashi, H., \& de Mejia, E. (2005). The genus Ardisia: a novel source of health-promoting compounds and phytopharmaceuticals. Journal of Ethnopharmacol 96(3), 347-354.

Le, T. M., Nguyen, T. H, Pham, T. T., Nguyen T. H, \& Le, T. L. C. (2005). Methods of analysis for fermentation technology. Hanoi, Vietnam: Science and Technics Publishing House.

Ling, L. F., \& Subramaniam, S. (2007). Biochemical analyses of Phalaenopsis violacea orchid. Asian Journal Biochemistry 2, 237-246.

MOH (Ministry of Health) (2010). Vietnam pharmacopoeia IV. Ha Noi, Vietnam: Medical Publishing House.

Nguyen, P. K. T. (2007). Methods of isolation of organic compounds. Ho Chi Minh City, Vietnam: National University Publishing House.

Nguyen, T. P. (1999). Handbook for searching and identifying families of angiosperms in Vietnam. Ha Noi, Vietnam: Agricultural Publishing House. 
Tran, L. T. K (2002). Study on chemical composition and biological activity of some Ardisia species of Myrsinaceae family in Vietnam (Unpublished Doctoral dissertation). Vietnam Academy of Science and Technology, Ha Noi, Vietnam.
Zhu, H., Wang, Y., Liu, Y., Xia, Y., \& Tang, T. (2009). Analysis of flavonoids in Portulaca oleracea L. by UVVis spectrophotometry with comparative study on different extraction technologies. Food Analytical Methods 3(2), 90-97. 